\title{
UM ESTUDO SOBRE A POSSÍVEL RELAÇÃO ENTRE A VIOLÊNCIA SEXUAL CONTRA A MULHER E A PORNOGRAFIA EXPLÍCITA NA SOCIEDADE CONTEMPORÂNEA
}

\author{
Maria luisa Candido Mazeu Ferreira* \\ Claudete de Souza*
}

\section{RESUMO}

O presente artigo objetiva investigar e identificar os primeiros registros da pornografia enquanto histórias sobre prostitutas, a sua evolução na sociedade contemporânea brasileira. Sua configuração alterou-se com o desenvolvimento da humanidade, sendo representada por cenas ou imagens obscenas ou sexo explícito, assim como suas interferências nos relacionamentos interpessoais. O trabalho visa refletir sobre a possível relação existente entre o grande acesso das pessoas aos conteúdos pornográficos disponibilizados, com a violência implicada ao sexo feminino, destacando as legislações vigentes que amparam as mulheres. Compreender o despertar da sexualidade sob a ótica do médico neurologista e psiquiatra Sigmund Schlomo Freud (1925) e observar as abordagens versadas pela escritora francesa Simone Beauvoir (1949) sobre o tema em questão. Ademais, refletir a respeito da manifestação dos ímpetos sexuais dos sujeitos e os danos que o acesso e excesso a produções pornográfica, virtual ou impressa, podem gerar. A realidade analisada, aponta que os dados coletados não são suficientes para comprovar que existe uma relação entre a pornografia e a violência sofrida pelas mulheres. Não há uma pesquisa acurada que confirma o questionamento deste artigo. Verifica-se a importância do diálogo e participação ativa dos adultos para com as fases iniciais da vida sexual de uma pessoa.

Palavras-chave: Pornografia. Violência sexual. Sexualidade.

\section{ABSTRACT}

This article objective to investigate and identify the first records of pornography while stories about prostitutes, their evolution in contemporary Brazilian society. Its configuration changed with the development of humanity, being represented by obscene scenes or images or explicit sex, as well as its interference in interpersonal relationships. The work aims to reflect about the possible relationship between the large amount of access of people to the pornographic content available, with the violence implied against the female sex, highlighting the current laws that support women. Understand the awakening

* Bacharel em Direito pela Universidade Metodista de São Paulo - UMESP. E-mail malumazeu@ yahoo.com.br

** Doutoranda em Educação na UMESP, Mestre em Direito na UNIMES - Universidade Metropolitana de Santos, Bacharel em Direito na Faculdade de Direito de São Bernardo do Campo - FDSBC. Advogada. Professora Orientadora. E-mail: claudete.souza@metodista.br. 
of sexuality from the perspective the neurologist and psychiatrist Sigmund Schlomo Freud (1925) and observe the tell presented by the French writer Simone Beauvoir (1949) about on the topic in question. In addition, to reflect on the manifestation of the subjects' sexual urges and the damage that access and excess to pornographic productions, virtual or printed, can generate. The analyzed reality points out that the data collected is not suficiente to prove that there is a relationship between pornography and the violence suffered by women. There is no accurate research that confirms the questioning of this article. It is verified the importance of the dialogue and active participation of the adults the initial phases of the sexual life of a person.

Keywords: Pornography. Sexual violence. Sexuality.

\section{INTRODUÇÃO}

Percebe-se que nas últimas décadas cresceu o número de mulheres que sofrem algum tipo de violência, quer seja verbal, física ou emocional. É um tema que nos leva a refletir, questionar e buscar respostas, que por vezes não conseguimos encontrar.

A origem do vocábulo violência, vem do latim vis que significa "o uso da força, constrangimento físico ou moral sobre outrem" ${ }^{\prime 1}$. A violência na história da humanidade sofreu diversas modificações sob a interferência cultural de cada local, de cada época, nas relações de poder, seja entre Estado e cidadãos, entre religiões, entre homens e mulheres, evidenciada, de formas distintas, dirigidas aos mais vulneráveis.

A construção da história se deu pela invenção da escrita, o que possibilitou os registros de personalidades e eventos no decorrer de toda a formação da humanidade. Constata-se que o modo como foram registrados os escritos e suas interpretações, relatam apenas parcialmente a história, dado que homens, em decorrência da classe social, assim como as mulheres, pela diferença de gênero, foram marginalizados, sendo-lhes tirada a oportunidade de se manifestarem e contribuírem para o enriquecimento da construção da história.

Pelos registros da história da humanidade, a figura feminina sempre esteve presente na criação e desenvolvimento do mundo, no entanto, não puderam contribuir com seus relatos devido à subordinação aos homens, uma vez que nenhum homem foi excluído dos documentos históricos em decorrência do sexo. Elas foram privadas educacionalmente, impedidas de conhecer e interpretar os documentos históricos, excluídas da formação de uma sociedade igualitária; isto posto, vê-se que a desigualdade social também é um tipo de violência.

Tal desigualdade é identificada no âmbito familiar e por vezes passa despercebida como algo banal e aceitável no cotidiano. Nesse sentido, Almeida (2013) discorre que é a:

...violência moral aí onipresente, considerada normal e naturalizada, a argamassa que mantém o sistema hierárquico, reproduzindo-o num tempo de tão longa duração que se confunde com a história da própria espécie. (ALMEIDA, 2013, p.[4]).

\footnotetext{
1 Etimologia da palavra conforme dicionário eletrônico de acordo com Aurélio Buarque de Holanda.
} 
É em virtude dos fatos sociais que nasce o Direito, mediante uma necessidade do ser humano em suas relações interpessoais. Uma ciência primordialmente social, que disciplina a vida em coletividade. Direito que, Reale $(2009$, p.2) define como uma "ordenação heterônoma, coercível e bilateral atributiva das relações de convivência, segundo uma integração normativa de fatos segundo valores".

Observa-se a realidade da sociedade contemporânea brasileira, em que o patriarcado ainda se faz presente. A diferença entre os gêneros resultou da criação e permanência de uma sociedade que produz e reproduz a violência sustentada pela desigualdade entre as pessoas. Mesmo com positivas mudanças sociais, este elemento é fundamentado pelas relações hierárquicas.

Outra ciência relevante para o desenvolvimento de uma sociedade mais humana são as abordagens da psicologia que tratam dos estados e processos mentais do comportamento do ser humano e de suas interações com um ambiente físico e social. Para essa área de estudo tem-se a saber da sexualidade sendo uma parte integrante da vida de cada sujeito, que contribui para a sua identidade ao longo de toda a vida. Essa esfera da vida humana instiga os pensamentos, sentimentos, ações e interações e, por conseguinte, influencia também a saúde física e mental do indivíduo. Por ser um fenômeno construído social e culturalmente, a sexualidade é influenciada, reestruturada e aperfeiçoada pelas práticas sociais existentes. (RIBEIRO, 2018, p.2)

Com o surgimento das primeiras civilizações manifestou-se, também, a origem da pornografia que se dá nas representações eróticas em pinturas, esculturas, fotografias, músicas e escritos que narram cenas de sexo. Percebe-se, por meio de estudos, que a partir da década de 1980 advieram movimentos críticos contra a pornografia, considerando que a mesma gerava vários tipos de violência e exploração, evidenciando o domínio dos homens sobre as mulheres.

Diante do quadro que se estabelece na sociedade contemporânea, nota-se que as tecnologias de informação disseminam com mais agilidade todo e qualquer tipo de comunicação e, dentro do contexto cultural, ocorre do mesmo modo com os conteúdos pornográficos, tanto em filmes, músicas, material impresso ou vídeos, remodelando a tradição cultural do passado.

A propositura deste estudo consiste, como objetivo geral, levantar um questionamento sobre a possível relação entre a violência sexual sofrida pelas mulheres com a pornografia explícita, principalmente aquela exposta na internet. O estudo visou investigar e identificar quais seriam as alternativas cabíveis para reduzir esse problema tão presente em nossa sociedade. Buscamos embasamento em artigos científicos e autores que versam sobre essa temática, tais como Moraes (1985); Lapeiz (1985), Chauí (1998), Abreu (2012), Dias (2016), entre outros.

A metodologia adotada, foi a pesquisa explicativa. Estudamos preliminarmente a história da pornografia como um todo e, seus desdobramentos ao longo do desenvolvimento das civilizações, fundamentando em livros históricos, artigos científicos e letras de músicas. Pesquisamos os fatores que permeiam esse tipo de relação na sociedade, impulsionando e influenciando o sujeito do sexo masculino 
e feminino ao modo como se dá o envolvimento sexual e, respectivamente seus impactos.

Adentramos ao campo jurídico, analisando as presentes leis nacionais que protegem a mulher no Brasil, seus avanços e conquistas. Não foi possível realizar uma pesquisa de campo, com entrevistas e relatórios que pudessem vir a enriquecer a pesquisa, devido ao prazo estabelecido.

\section{FUNDAMENTOS DO CULTO DA PORNOGRAFIA PELO SER HUMANO}

A palavra pornografia vem do grego, pornographos, sendo definida por contos sobre prostitutas. Esse tema literário da Grécia Clássica perdurou por muitas eras, tendo início nos séculos IV e V a.C. O escritor Nuno Cesar Abreu disserta sobre a pornografia, afirmando que "além de ser 'escrito acerca do comércio sexual', seu significado nos dicionários indica a expressão ou sugestão de assuntos obscenos na arte, capazes de motivar ou explorar o lado sexual do indivíduo." (ABREU, 2012, p. 21).

No decorrer dos tempos, a pornografia foi modificada, tanto pelas proibições da Igreja Católica, como pela transformação moral e social do homem presente na sociedade. O historiador francês de Literatura Erótica, Sarane Alexandrian², afirma que "aos poucos, qualificou-se como pornográfico tudo o que descrevia as relações sexuais sem amor". (ALEXANDRIAN, 1994, p.1).

A representação do corpo humano em sua variedade de formas existe desde que o homem desenvolveu a capacidade para representar algo e, tem-se como exemplo primário, as pinturas rupestres, imagens datadas de quatro mil anos a.C., de vários lugares e culturas (DI ANGILLIS, 2016) ${ }^{3}$. A famosa escultura paleolítica, Vênus de Willendorf, esculpida em calcário, entre 28.000 e 25.000 anos a.C., de aproximadamente onze centímetro de altura, como exemplo, foi uma idealização feminina, que retrata uma mulher nua, com a vulva, seios e barriga extremamente volumosos. Pouco se sabe sobre sua origem, sua criação e significado cultural, no entanto, historiadores apontam uma forte relação com o conceito de fertilidade; é também identificada como a deusa Mãe-terra.

A humanidade, em sua constante evolução passou, gradativamente, a representar com mais especificidade o corpo feminino e masculino. Os povos antigos da Grécia e Itália eram admiradores das representações dos corpos nus, bem definidos e o amor sexual retratado de forma artística.

A liberdade sexual presente na Grécia, 400 a.C., aceitou positivamente as representações do sexo, apresentados em desenhos eróticos nos vasos e paredes, em estátuas, cânticos, dentre outras. O sexo é um elemento marcante nas histórias gregas antigas, e faz parte das origens de alguns deuses, como Eros, o deus do amor,

Filósofo francês, ensaísta e crítico de arte.

3 Extraído da entrevista disponível no youtube do autor Guilherme Di Angilis, enquanto escrevia sua tese de doutorado, título: O erótico da pornografia: as imagens, sons, e escritas nas representações sobre sexo. 
e da paixão, Afrodite, a deusa que representa - além do amor -, o prazer e desejos carnais; e Dionísio, o deus das festas e do prazer. (RAMOS, 2019, p.1).

Nos contos mitológicos, as missões e aventuras dos deuses se interligavam com as relações sexuais. O historiador Paul Chrystal compilou e organizou informações sobre o tema e publicou o livro In bed with the Ancient Greek, traduzido para o português "Na cama com os Gregos Antigos". Na obra ele narra os costumes sexuais das civilizações antigas. (BARREIROS, 2020, p.2).

Nos contos de aventuras sexuais, se encontra as relações homossexuais, algo comum e aceito na sociedade grega, assim como a masturbação, considerada natural entre todas as pessoas; e a prostituição era regulamentada. Havia também a simbologia mitológica da sexualidade com Sátiro e Ninfas. ${ }^{4}$.

Em Roma, a relação com a sexualidade não era diferente, pois ocorria um incentivo para as práticas sexuais. O poeta romano Públio Ovídio Naso, foi considerado um dos maiores do século I a.C., conhecido pelo perfil erótico em seus trabalhos. Destaca-se a obra Ars Amatoria "A arte de amar", que aborda a sedução e o jogo amoroso, um guia do sexo. A intensidade dos cidadãos em manifestar seus ímpetos sexuais, deu espaço para os escritos sobre prostitutas e orgias, modificando assim os contos eróticos para pornographos.

Já no oriente, o hindu Vatsyayana elaborou o Kama Sutra ${ }^{5}$, escrito na Índia no século II d.C., compilando manuscritos em forma de livro. Essa obra foi preparada com intuitos religiosos, pois, para o hinduísmo, a palavra Kama significa amor, prazer, satisfação e, Sutra significa guia, manual. Portanto, este livro que descreve aproximadamente 529 posições sexuais defende a liberdade sexual e auxilia seus seguidores na melhoria do Kama. Entende-se que o sexo é parte da criação divina, por isso a prática e a veneração.

Na Grécia Clássica, séculos IV e V a.C., é possível encontrar conteúdos pornográficos em seu sentido original. Um conto muito famoso dessa época é $O$ Banquete, de Platão, que relata a pederastia ${ }^{6}$ (MOARES; LAPEIZ,1985, p.19).

A peça cômica de Aristófanes, cujo nome da obra é Lisístrata, conta a história de uma dama de Atenas e outra de Esparta que propõem às demais mulheres de seu respectivo povo que tomem o tesouro público e façam greve sexual aos maridos que foram para a guerra, afim de que seja firmada a paz.

4 Sátiro vem do grego "sátyros", era uma divindade da natureza, uma figura masculina representada com orelhas grandes e pontiagudas, nariz achatado, chifres pequenos, com rabo e pernas de cabra. Ninfa deriva do grego "nymphe". As ninfas eram divindades femininas, pequenas, associadas à fertilidade, representando as forças elementares da natureza, eram criaturas que não envelheciam. Ligadas à terra e à água, eram classificadas segundo o lugar em que habitavam, como florestas, vales, montanhas, cursos d água. Ambas as figuras mitológicas eram personagens dos contos eróticos, sendo a Ninfa alvo da luxúria do Sátiro.

5 Tradução da palavra extraída do portal https:/ / www.sexestima.com.br/a-historia-do-kama-sutra/

6 É a designação para a relação de amor de um homem mais velho por um jovem, um adolescente, considerado como um rito de passagem. Não havia censura moral para os relacionamentos homossexuais entre homens adultos e homens jovens livre; tinha-se a ideia de que dessa forma o conhecimento e a virtude do homem adulto seriam passados ao homem jovem. 
No século VI, no início da Idade Média, os clérigos católicos formalizaram a lista dos pecados capitais e nela constava a luxúria, sendo compreendido que entregar-se aos prazeres carnais afastava os cristãos da santificação. Isto posto, "a castidade física, tanto para os homens quanto para as mulheres se impôs na vida e na arte. [...] E para dominar as tentações dos prazeres da carne a Igreja não hesitou em empregar métodos extremos. " (MOARES; LAPEIZ,1985, p. 23). Ainda assim, haviam andarilhos contadores de história que se apresentavam em tabernas narrando contos pornográficos.

No século XIII, a Igreja Católica Romana criou a instituição do Santo Ofício, também conhecida por Inquisição. Eram perseguidos todos aqueles que pudessem vir a ameaçar as práticas doutrinárias da Igreja, sendo muitos condenados à fogueira ou ao exílio.

A sexualidade foi um tema discutido pelo cristianismo, por intermédio de orientações doutrinárias e por códigos morais. Havia uma grande preocupação com a vida sexual da sociedade ocidental, quando a Igreja utilizava instrumentos de controle para manter os desejos carnais sob seu poder, com o intuito de dominar a sexualidade dos fiéis.

A doutora em psicologia social, pela PUC de São Paulo, Bruna Suruagy do Amaral Dantas, em seu trabalho de pesquisa, comenta que:

[...] a Igreja recomendou aos fiéis renunciar de forma definitiva a atividade sexual e conter os desejos, impedindo sua manifestação. A virgindade foi promovida pelo clero católico ao status de santidade máxima, estado que todo cristão deveria almejar. Todavia, diante da recusa de boa parte da sociedade de atender às orientações eclesiásticas, a Igreja promoveu a sacramentalização do casamento a fim de ampliar seus poderes de intervenção na intimidade do casal e trazer a sexualidade para seu domínio. A sexualidade, pois, atuou como importante dispositivo de poder, garantindo o fortalecimento político da instituição cristã na sociedade ocidental. [...] $\mathrm{O}$ ato sexual começou a ser tratado como obrigação dos cônjuges, não devendo, no entanto, ser acompanhado por desejo erótico. Apesar de ser obrigatório, o sexo no matrimônio foi considerado pecado por alguns sacerdotes até o século XV. O casamento não era capaz de purificá-lo, embora reduzisse sua imundície. Muitos teólogos mantiveram-se reticentes em relação às práticas sexuais entre cônjuges, apesar da sacramentalização do matrimônio. A sexualidade conjugal deveria restringir-se à reprodução, o que não significava que estava livre do estigma do pecado. (DANTAS, 2010, p. 2).

A Igreja ensinava e determinava como seus fiéis deveriam realizar suas relações sexuais, com a criação de um conjunto de leis atribuídas à regularização da relação conjugal e, assim, eram aceitas devido ao temor divino fortemente presente.

Dentre as obras mais conhecidas desse gênero literário, Decameron, publicado em 1371 por Giovanni Boccaccio, tem como plano de fundo a peste que se instalou em Florença no século XIV. Para fugir do contágio, três homens e sete mulheres se mudam para uma vila, e a todo tempo contam histórias. São narradas, ao todo, 100 
histórias acerca de mulheres sendo seduzidas por seus amantes e das aventuras dos maridos infiéis. O centro das obras de Boccaccio, produzidas de forma anedótica e atroz, é a Igreja. Tais obras foram proibidas pelo Papa Paulo IV, e seu autor, condenado à prisão pela Inquisição. (MORAES; LAPEIZ, 1985, p. 26).

Seguindo a mesma linha de trabalho de Boccaccio, que fazia referência à luxúria dos religiosos e à sedução de monjas por sacerdotes, Maguerite de Valois, esposa do Rei Henrique IV de Navarra, produziu o livro Heptameron, um dos únicos exemplares da literatura erótica de autoria feminina. No entanto, sua obra apenas foi publicada em 1558, alguns anos após sua morte. (MORAES; LAPEIZ, 1985, p. 26).

O Renascentismo foi um período histórico e um movimento cultural, intelectual e artístico que nasceu na Itália, durante a transição da Idade Média para a Moderna, entre os séculos XIV e XVII. O "novo nascimento" indicou a cinesia de retomada da cultura clássica greco-romana, fluxo que se expandiu para outras regiões europeias. O período Renascentista modificou o ideal de virtude e castidade em decorrência das ideias iluministas, o que enfraqueceu a rígida moral sexual cristã. (MORAES; LAPEIZ, 1985, p.27). Tal mudança propôs o ressurgimento consciente do passado compreende-se essa fonte como o engrandecimento do homem e da natureza, em objeção ao divino e ao sobrenatural, conceitos estes presentes na cultura da Idade Média.

Nesse período da história, surge a figura do libertino ${ }^{7}$, na França, considerado filósofo e revolucionário. Os libertinos contestavam e questionavam, nos romances, cujo tema central era o prazer sexual e o prazer do conhecimento, o moralismo religioso, atingindo os valores morais e cristãos. Apresentavam como personagens fictícios dessa literatura o padre, o monge, fiéis, freiras, tendo como cenário os espaços sagrados para a Igreja. (MORAES; LAPEIZ, 1985, p.47).

É configurada e confirmada no século XVIII a libertinagem ${ }^{8}$, uma anarquia moral, pois é notório que a literatura libertina era contra os costumes e a moral social e religiosa da época. Identifica-se uma relação dos libertinos com as histórias pornográficas que naquele período era de cunho crítico, um modo de expressar a inconformidade com as condutas da Igreja Católica e as imposições da nobreza. (ABREU, 2012, p. 43).

No século XIX nasce a fotografia, um novo mecanismo revolucionário que surpreendeu e agradou as pessoas da época, sendo de grande valia para registrar momentos e imagens para estudos, auxiliando diversas áreas como a medicina, ciência, jornalismo. Sob outra perspectiva, a fotografia possibilitou o crescimento de retratos obscenos. Surgem então, em conjunto com a vasta literatura pornográfica,

7 A etimologia da palavra vem de liberto, homens pensadores e literatos europeus que se abstraíam dos princípios morais do seu período, como aqueles relacionados à moral sexual sendo caracterizado também como um hedonismo extremo, conhecido pelo espírito livre ou livre-pensador. Foi uma classificação criada no final da Idade Média tendo algumas definições como "desregramento de costumes", "indiferença às coisas da religião", "aquele que não respeita as interdições e segue as inclinações do corpo e do espírito".

8 Conduta de pessoa que se entrega imoderadamente a prazeres sexuais; à prática do libertino. 
com inspirações no sadomasoquismo ${ }^{9}$, as primeiras revistas e almanaques pornográficos, com imagens, desenhos e ilustrações de corpos nus e relações sexuais. (MORAES; LAPEIZ, 1985, p. 32).

A título de curiosidade: foi descoberto no início do século XIX, em Deir el-Medina, no Egito, uma vila operária, um rolo de papiro egípcio criado no período de Ramesside, 3.000 anos antes. Os antigos egípcios confeccionaram um diagrama de doze posições sexuais diferentes, chamado de "Papiro erótico de Turin", pois este se encontra guardado no museu de Turin, Itália. O papiro impactou os historiadores, visto que retratam o sexo apenas entre seus deuses e de modo sutil nas pilastras das pirâmides. O papiro erótico foi apelidado de "primeira revista pornográfica". ${ }^{10}$

No século XIX, por volta do ano de 1870, chegavam ao Brasil as primeiras fotografias da nudez feminina, juntamente com os livros eróticos. Os editores brasileiros notaram uma vigorosa satisfação do público que consumia tais conteúdos, passando a investir nas produções nacionais, lançando livros tachados de "romances para homens", mantendo seus autores no anonimato. (MORAES; LAPEIZ, 1985, p. 62).

Em decorrência desse feito, o crescimento da fotografia possibilitaria que as pessoas tivessem contato com as primeiras imagens em movimento. Surgiu o cinema, no ano de 1894, com uma apresentação pública realizada pelos irmãos franceses Lumière, num curta metragem de 46 segundos, "A saída dos operários da fábrica Lumière em Lyon". (NUNO, 2016, p. 18).

É sabido que o ocidente aspirava a pornografia já no século XX. Os livros eróticos ainda faziam muito sucesso, relatando grandes romances, provocantes orgias, fantasias eróticas de prazer e dor. Contudo, os avanços tecnológicos proporcionaram a popularização da pornografia e, em razão dos investimentos no cinema, iniciaram também as produções de filmes pornográficos. (MORAES; LAPEIZ, 1985, p.34).

O cinema chegou ao Brasil em julho de 1896, tendo sua primeira exibição na cidade do Rio de Janeiro numa sala aberta ao público, apresentando diversos filmes curtos que retratavam o cotidiano das cidades europeias. Inicialmente as produções brasileiras eram de caráter documental, e gradativamente, os demais gêneros foram sendo inseridos.

Durante o período da ditadura no Brasil, na década de 1960 inicia-se o Cinema Novo Brasileiro, movimento cinematográfico em prol da autenticidade da arte brasileira, com produções influenciadas pelo contexto social, político, econômico e cultural, retornando, assim, nesse período, a produção de filmes eróticos que obtiveram espaço para suas criações e exibições. (BERNARDET, 1978, p. 96).

Um ícone do cinema novo brasileiro é o filme "Os cafajestes", de Ruy Guerra, que mostra a atriz Norma Bengell correndo seminua na praia. Além deste há outras filmagens que seguiram a mesma forma de expor a sensualidade feminina, como "Bonitinha mas ordinária" de Nelson Rodrigues (1963), e "Noite vazia" de

9 Perversão sexual que resulta da combinação de sadismo e masoquismo.

10 Disponível no canal History: https://br.historyplay.tv/noticias/conheca-primeira-revista-pornografica-da-historia 
Walter Hugo Khoury (1964)". (MORAES; LAPEIZ, 1985, p.66). Tais trabalhos alavancaram o erotismo no cinema nacional, nascendo, em 1970, no Bairro da Luz, região chamada "Boca do lixo", em São Paulo, uma nova modalidade de produção, que os cineastas nomearam como "pornochanchada". (KREUTZ, 2019, p. 3).

A pornochanchada é a combinação do humor com o erotismo, com mulheres sensuais, histórias românticas, exploração da virgindade, adultério, caracterizada ainda por títulos de duplo sentido, um gênero cinematográfico inspirado nas comédias populares da Itália dos anos 1960. Paralelamente, também eram produzidos, em pequena proporção, filmes pornográficos.

Sexo, nos filmes pornôs, é tratado de maneira grosseira, num clima denso e obsessivo, tanto nas telas, quanto na escolha de atrizes. Anúncios de jornais, prometendo a quem quiser ser artista uma carreira meteórica e fulgurante, alimentam o mercado cinematográfico com corpos jovens. Iludida pelo sucesso, presa fácil dessa armadilha é a mulher, produto indispensável para os pornôs. (MORAES; LAPEIZ, 1985, p. 67)

A vasta exposição dos corpos femininos conquistou demasiadamente o público masculino, enquanto a promessa de sucesso aliado à facilidade de ganhar dinheiro, motivou muitas mulheres a aceitarem as propostas de trabalho como "atrizes" de filmes nacionais. Além dos filmes, as revistas pornográficas expostas nas bancas de jornais incitavam o consumidor à compra, garantindo um rendimento satisfatório aos editores das revistas. (MORAIS; LAPEIZ, 1985p. 69).

Após mais de quinze anos de sucesso, os filmes da pornochanchada entraram em declínio com o mercado pornográfico nos anos de 1980. Naquela mesma década, a circulação de revistas pornográficas retornou com robustez, chegando a mais de cem títulos à venda.

Sem expor qualquer conteúdo escrito, “ $80 \%$ das revistas acionam o sentido da visão masculina [...] estas revistas não têm como ponto forte a matéria escrita, privilegiando basicamente o visual até em seu material promocional que oferece ao público consumidor". (MORAES; LAPEIZ, 1985, p.71). O mercado das revistas pornográficas gerou muita renda aos seus editores.

No final dos anos 1980, a internet chega ao Brasil e, assim como ocorreu nos demais países do mundo, seu acesso inicialmente era bem restrito, visando mais a auxiliar no âmbito acadêmico e, posteriormente, ampliou-se para usuários de empresas e domésticos.

A socialização dessa mídia globalizada estendeu-se ao público, sucedendo a amplificação de conteúdos produzidos e disseminando-os na internet, tornando-se um meio de comunicação abrangente. Nessa plataforma virtual, a pornografia ganhou maior visibilidade, dado que o anonimato é algo sempre presente, privilegiando aqueles que não desejam que sua família saiba que curtem pornografia. Desde a propagação pela internet, além de filmes pornográficos foram lançados vídeos em sites específicos, intensificando a produção e o consumo da pornografia hardcore ${ }^{11}$.

11 A pornografia hardcore é um termo designado para o sexo explícito em todas as suas formas, detalhando os corpos e a relação ali exposta. 
Os meios de comunicação social são ferramentas que possibilitam a interação entre os indivíduos, têm caráter informativo e de entretenimento, por meio de linguagens, seja pela escrita, por meio de jornais, livros e revistas; seja pela linguagem sonora, a partir da música; pelo audiovisual e multimídia, apresentando a televisão e a internet. A pornografia se faz presente na internet, por meio de sites específicos, nas músicas de cunho pornográfico e na televisão, pela TV fechada que propicia canais com esse mesmo conteúdo.

A música é um elemento linguístico que estimula os sentidos do corpo humano e que possibilita uma fácil integração social e cultural. Há dois polos que concretizam os efeitos musicais: a emissão do som e a receptação da mensagem, ou seja, quem comunica, por meio do som, e aquele que recebe a comunicação. (FONSECA, 2017, p.2).

Há gêneros musicais que fazem apologia e incitam a pornografia, letras que além de expor atos sexuais, empregam a figura feminina como um objeto a ser usado pelo homem. Alguns sambas e pagodes já foram gêneros musicais que apresentaram letras obscenas, mas entraram em cena o funk, com o baile pancadão furacão 2000, o sertanejo moderno e o axé baiano, que intensificaram a obscenidade presente nas letras.

Para caracterizar a pornografia numa música é necessário analisar o conjunto da obra, a letra, os sentidos conotativo e denotativo e o entendimento social. A forma como produzem e divulgam esse gênero é vista por muitos como entretenimento, independente de analisar quais as sensações, emoções e efeitos que as letras podem gerar no consciente e no inconsciente das pessoas.

Com a difusão pela internet a partir da década de 1990, foi gerado um público globalizado, interligado mundialmente. Então, o material pornográfico encontrou uma nova possibilidade de se consolidar, oferecendo nessa extensa plataforma de comunicação e interação tais conteúdos aos seus usuários. A internet possibilitou um amplo espaço para os sites pornográficos, o que proporcionou a sua popularização, acessibilidade, privacidade e comodidade aos navegadores.

Na mídia digital são divulgados vídeos em sites específicos que disponibilizam a pornografia. Inicialmente se encontrava sexo explícito, visando atender ao público masculino, por ser o grupo social que mais consome esse material. Com o passar do tempo, cresceu consideravelmente o número de vídeos publicados e, além de exacerbar a quantidade de sites disponíveis para a divulgação desse conteúdo, as produções abrangeram também temas que foram do agrado do público feminino. (VINHAL, 2018, p. 2).

Os usuários de sites pornográficos possuem o poder de opinar sobre quais modalidades de sexo querem assistir. Tal possibilidade acarreta mudança constante das produções pornográficas, haja vista que o sexo explícito ou pornografia mainstream (convencional) não satisfaz mais o público na mesma proporção.

Uma das redatoras do site Gazeta do Povo apresentou em seu artigo "Exposição à pornografia deixa marcas para toda a vida" uma breve análise do livro "Os custos sociais da pornografia" (The Social Costs of Pornography) escrito pela 
psiquiatra canadense Norman Doidge. Esclarece que a pessoa se acostuma com alguns desempenhos apresentados nos vídeos e com o tempo procura porções mais fortes para alcançar os mesmos resultados. A consequência do consumo constante, seria a perda do prazer nas relações sexuais reais e sadias. (DRECHSEL, 2016, p. 1).

Em razão da constante evolução da internet e, em decorrência do vasto acesso e consumo da pornografia nesse meio de comunicação, nota-se a expansão do negócio, tornando-se uma grande indústria do sexo, pois há oferta de produtos e há quem os consuma, exigindo produções cada vez mais pornográficas e que satisfaçam os desejos dos usuários dos sites.

O mercado pornográfico cresceu e se fortaleceu, se tornando uma indústria multimilionária, extremamente lucrativa e pouco regulamentada. Tendo em vista a concorrência entre os sites e os vídeos divulgados, fez-se necessário aumentar a produção e divulgação dos conteúdos. Assim sendo ocorreu uma maior exploração dos atores ali envolvidos, principalmente as atrizes, comumente submetidas a maior violência.

\section{SEXUALIDADE: SEU DESENVOLVIMENTO E A INTERFERÊN- CIA DA PORNOGRAFIA}

Ao longo de diversos estudos e elaboração de teorias, todos associados aos conflitos psíquicos do ser humano, Freud constituiu a teoria da sexualidade, apontando-a como alicerce da vida psíquica, exposta no livro Três ensaios sobre a teoria da sexualidade. O médico neurologista e psiquiatra Sigmund Schlomo Freud é considerado até os dias de hoje o pai da psicanálise. (FREUD, 1925).

As teorias de Freud seguem o idealismo evolucionista, pois "inspirando-se em Darwin, fazem do grupo social um fato originário, oriundo de necessidades distintas daqueles do grupo familiar. Cada um tem sua origem psicológica própria, um não deriva do outro.". (VALAS, 1997, p. 10). A partir dessa explanação, é possível constatar que Freud não concordava com as imposições sobre a sexualidade em seu tempo, por entender que há uma profundidade na singularidade de cada indivíduo, sendo homem ou mulher.

De acordo com a sociedade do século $X X$, a sexualidade estava interligada unicamente à relação sexual, especificamente à reprodução humana. Por intermédio dos estudos da psicanálise, Freud trouxe um novo pensamento para a palavra sexualidade. Aponta que todos os movimentos vitais se inclinam à proteção do indivíduo, como também, admitem um quantum de satisfação erótica ou de negação desse prazer, percebe-se que há libido investida em todos os atos psíquicos. (FERREIRA; MENESES, 2011, p. 1).

Freud, ao explicar as aberrações sexuais em seu livro, define o que pode ser a libido, a partir da psicanálise:

O fato da existência de necessidades sexuais no homem e no animal expressa-se na biologia pelo pressuposto de uma "pulsão sexual". Segure-se nisso a analogia com a pulsão de nutrição: a fome. Falta à linguagem vulgar [no caso da pulsão sexual] uma designação equivalente à palavra 


\begin{abstract}
"fome"; a ciência vale-se, para isso de "libido". A opinião popular faz para si representações bem definidas da natureza e das características dessa pulsão sexual. Ela estaria ausente na infância, far-se-ia sentir na época e em conexão com o processo de maturação da puberdade, seria exteriorizada nas manifestações de atração irresistível que um sexo exerce sobre o outro [...]. (FREUD, 1925, p.84)
\end{abstract}

Dissemelhante da sexualidade, que inicia seu afloramento ainda na infância, nota-se que a libido é algo intrínseco ao ser humano, porém, manifestada pelo contato com outro sujeito, no decorrer de outras fases da vida.

Com base no livro abordado e por meio de estudos aprofundados, observa-se que o modo pelo qual a libido é investida, poderá causar danos ao indivíduo em decorrência da falta de zelo com sua integridade física e mental. Outro fato apontado é a possibilidade de causar algum prejuízo à sociedade, um dano a terceiro, o que afeta a ordem social. Tendo em vista essa perspectiva, o considerado dentro da normalidade passa a se tornar anormal.

A obra Três ensaios sobre a teoria da sexualidade é um estudo analítico de extrema profundidade, que aponta uma vasta compreensão do ser humano, um ser sexual. Compreende-se a singularidade de cada indivíduo, cada um possui sua origem psíquica que se desenvolve ao longo das experiências vivenciadas.

Segundo Freud, a contradição entre os anseios do indivíduo e o convívio em sociedade acarreta um tormento psíquico. Patrick Valas, no livro "Freud e a perversão", afirma que "o instinto sexual em seu desenvolvimento influencia os mais elevados sentimentos sociais, morais e religiosos da humanidade" (1997, p.10). Certifica-se, portanto, que o desejo sexual seria a energia motivacional primordial da vida humana.

O tema discutido, a sexualidade, é um ponto de difícil discussão familiar e social, no entanto, é vero reconhecer ser um fenômeno intrínseco ao corpo humano, um despertar de desejos e emoções naturais do homem e da mulher, que aflora desde a fase infantil dos mesmos.

O escritor Nuno Cesar Abreu, no livro "O olhar pornô: a representação do obsceno no cinema e no vídeo", aborda o assunto da seguinte forma:

Sexualidade é algo massivamente presente em nossa cultura, mas quase sempre sujeito a limitações. Embora tenha sido exaustivamente definida por uma série de discursos especializados (medicina, psiquiatria, criminologia, sexologia etc), suas manifestações públicas se apresentam mais por alusão do que por descrição. Formas de humor, representações da mulher, roupas (a moda), as intenções eróticas implícitas na publicidade, entre outras práticas, sempre evocam sexualidade. (ABREU, 2012, p.47)

A partir da definição apresentada pelo autor, é possível relacioná-la com o consumo de pornografia na sociedade contemporânea, assunto este abordado anteriormente. Abreu afirma que, 
zar as representações interditas, assegurando sua circulação no espaço permissivo instituído na encruzilhada das incertezas, do moralismo, da liberação dos costumes e seus amparos legais. (ABREU, 2012, p. 47).

Observa-se que a sociedade contemporânea sofre grande interferência das mídias sociais, o que acarreta mudanças no comportamento dos sujeitos e nas suas relações interpessoais, tendo em vista o conteúdo ali exposto. Em decorrência de tais transformações socioculturais, os sociólogos e filósofos alemães Theodor Adorno e Max Horkheimer originaram o termo indústria cultural.

O consumo dos meios de comunicação, como, por exemplo, a internet, cumpre um papel de propagar uma ideologia que transpassa as relações sociais, uma mídia que se naturaliza no modo de vida das pessoas. Os indivíduos, atingidos pela comunicação de massa realizada pela mídia em geral, ocasionam uma reflexão sobre o modo de constituição das relações interpessoais, acarretando um novo modelo de sexualidade na atual sociedade.

Tendo em vista a efetiva presença da indústria cultural, a pornografia também se apropria desse espaço de influência. Constata-se que,

Com o desenvolvimento da indústria cultural, a pornografia se traduz em produtos, de acordo com os princípios de produção em massa. A representação transgressiva da sexualidade ganha formatos e padrões, tornando-se mercadoria, cuja circulação se faz influente na estruturação da sexualidade nas chamadas sociedades de consumo. (ABREU, 2012, p. 48).

A pornografia comercializa, de modo miserável, a ideia de provocar instintos que agucem os desejos sexuais de quem a consome. É possível caracterizar uma relação comercial, pois há um produto oferecido e o sujeito que o procura.

Oferecendo sexualidade como mercadoria embalada sob forma discursiva, ele possibilita a liberação catártica (em sentido amplo) das fantasias (reprimidas ou não) de seus consumidores - mentes e corpos libertinos, liberais, libertários ou moralistas -, transformando seus fetiches em desejo ou seus desejos em fetiches. Há para todos os gostos e apetites. (ABREU, 2012, p. 49).

A exploração sexual é um fator clarividente na atual sociedade, haja vista que a produção de pornografia exibe vídeos agressivos a quem é exposto, tanto de frente para as câmeras, como para quem consome a produção pronta.

A sexualidade é algo inerente à vida do homem e da mulher, sendo natural a busca por algo que venha trazer algum tipo de satisfação sexual. Nota-se, também, que a pornografia abusa do íntimo do indivíduo, pois explora de forma violenta o corpo de quem atua e, consequentemente, prejudica a vida real de quem consome.

A falta de diálogo sobre a sexualidade e os meios de explorá-la seria a causa para o grande consumo de pornografia e, consequentemente, a produção de conteúdo? Sabe-se, que se produz aquilo que o consumidor deseja. A inexistente investi- 
gação do indivíduo ao atentar-se com o próprio autoconhecimento e autocuidado, pode acarretar transtornos psíquicos que podem vir a afetar o desenvolvimento saudável da sexualidade do mesmo.

Há duas questões preocupantes a serem analisadas: o perfil de quem consome pornografia e a exploração de quem está sendo ostentado. Como já elucidada, apresentando a análise feita por meio de estudos de Freud, a sexualidade é algo intrínseco a cada pessoa e o modo pelo qual ela é explorada poderá acarretar consequências danosas para o próprio sujeito ou afetar terceiros.

A escritora Simone Beauvoir, em sua obra intitulada "O segundo sexo - 2. A experiência vivida", descreve o desenvolvimento da sexualidade para a mulher e para o homem. A priore, descreve:

Para o homem, a passagem da sexualidade infantil à maturidade é relativamente simples: há objetivação de prazer erótico que, em lugar de ser realizado na sua presença imanente, é intencionado em um ser transcendente. A ereç̧ão é a expressão dessa necessidade; sexo, mãos, boca, o homem volta-se com todo o corpo para a parceira, mas permanece no centro dessa atividade, como em geral o sujeito em face dos objetos que percebe e dos instrumentos que manipula; projeta-se no outro sem perder sua autonomia, a carne feminina é para ele uma presa e ele apreende nela as qualidades que sua sensualidade reclama de todo objeto [...]. (BEAUVOIR, 1949, p. 109).

Por um rapto real ou simulado é que a mulher era outrora arrancada de seu universo infantil e jogada na sua vida de esposa; é a violência que a faz passar de moça a mulher: diz-se também "tirar" a virgindade de uma jovem, "tomar-lhe" a flor. Essa defloração não é o fim harmônico de evolução contínua, é a ruptura abrupta com o passado, o início de um novo ciclo. (BEAUVOIR, 1949, p. 110).

A sociedade incentiva o desenvolvimento da sexualidade masculina, tratando com naturalidade o ato da masturbação e o contato com a pornografia. O menino, tendo tal conteúdo como a base da representação do sexo, o aceita como o real das relações sexuais, praticando-o com outro sujeito.

Ao se atentar com o chamado "segundo sexo", o sujeito do sexo feminino tem o desenvolvimento da sua sexualidade limitada. O desabrochar do corpo feminino é mais complexo e profundo para se compreender de modo tão prático e objetivo, como se nota a singular percepção da autora. Observa-se que a sexualidade feminina é um tabu perante a sociedade, mas que vem ganhando espaço para debates atualmente.

Na época atual, é possível observar a capacidade das crianças em saber manusear celulares e computadores. Compreende-se que as mesmas não possuem na fase infantil o amadurecimento e discernimento necessário para acessar determinados conteúdos disponíveis na internet.

Todo ser humano é um ser sexual, portanto, desde a fase inicial da vida, nossos instintos são aflorados naturalmente. O sujeito do sexo masculino, ainda quan- 
do criança, é inserido no vasto mundo pornográfico, principalmente nos dias de hoje, além de incentivado por homens já na fase adulta, por acreditarem ser algo normal e um meio de aprendizado.

A problemática de uma criança ter contato precocemente com conteúdo pornográfico é pelo fato de moldar sua percepção sobre sua sexualidade e sobre o sexo. Quanto mais se reproduz a ideia de que vídeo pornográfico é educativo, mais ele será compreendido como verdadeiro, e tal ocorrência pode ser indicada por uma confirmação aceita pela sociedade. (DINES, 2019, p. 2) ${ }^{12}$.

Mesmo diante da luta e conquistas de mudanças sociais, a figura feminina tem suas primeiras concepções sobre o sexo em conjunto com o indivíduo que já presenciou a pornografia. O sujeito consome um produto irreal, na certeza de que a prática do que lhe foi dado é satisfatório e prazeroso para ambos os envolvidos na relação sexual. (DINES, 2019, p. 2).

Outra questão a ser observada, é a objetificação dos corpos, tendo como ponto central, o corpo feminino. Ao longo dos anos, os vídeos pornográficos passaram a ser mais agressivos e humilhantes para com as atrizes em suas atuações, devido à intensa procura dos consumidores.

O básico já não serve para satisfazer os desejos de quem acessa os sites pornográficos, e os produtores, tendo em vista a necessidade de acompanhar os anseios de seus usuários, não os deixa insatisfeitos, procurando sempre surpreendê-los com novas produções, independente da integridade física e mental dos atores ali apresentados.

III A EVOLUÇÃO DO DIREITO PROTETIVO E A VIOLÊNCIA CONTRA A MULHER A PARTIR DA CONSTITUIÇÃO FEDERAL DE 1988 SOB A ORIENTAÇÃO DO PRINCÍPIO DA DIGNIDADE DA PESSOA HUMANA

O Estado, na função de organizador do ordenamento jurídico e defensor dos interesses difusos e coletivos de uma sociedade, menciona o Direito como o meio de regulamentar as relações entre seus indivíduos e, dando amparo aos interesses dos sujeitos, garantindo a efetividade dos princípios da Carta Magna. (MANSSUR, 2019, p. 2).

A Constituição Federal de 1988 disciplina com soberania sobre os direitos e garantias fundamentais e tutela do maior bem jurídico, a vida. Os doutrinadores Gianpaolo Poggio Smanio e Humberto Barrionuevo Fabretti definem o bem jurídico sendo,

Os interesses sociais que, por serem caros à sociedade, merecem a proteção da ordem jurídica são chamados de bens jurídicos. Assim, todos os bens jurídicos são interesses vitais dos indivíduos ou da comunidade que, em determinado momento, passaram a necessitar da tutela do sistema jurídico." (SMANIO; FABRETTI, 2017, p. 99).

12 Gail Dines, britânica, professora emérita de sociologia, é ativista antipornografia, concedeu uma entrevista à revista TPM. 
Segundo o sociólogo Émile Durkheim, as relações humanas são desvirtuadas pela violência, necessitando de normas que as orientem, não podendo o fato social contrariar o ordenamento jurídico. $\mathrm{O}$ andamento do processo civilizatório, ocasionou diversas formas de violência, uma vez que as sociedades apresentam anseios diversos, sendo que a cada anseio há uma violência correspondente. (LACERDA, 2014, p. 6).

Nesse sentido, a violência contra a mulher é um problema enfrentado por diversos países, independentemente de fatores sociais e culturais. No Brasil, a incidência de violência contra a mulher é substancial, envolvendo agressões verbais e físicas, promovidas pelos membros da própria família ou pessoas de outros locais os quais a vítima frequenta, como afirma a advogada, jurista e professora de Direito Penal, Ivete Senise Ferreira, na obra "A mulher e o Direito" (2008). Pode ser entendida como um fenômeno complexo e plural, a partir de fatores sociais, históricos, culturais e subjetivos, não se limitando a nenhum deles. (BARUS-MICHEL, 2011, p. 2) ${ }^{13}$.

Jaqueline Soares Magalhães (2003, p. 33), disserta que:

A violência implica em ausência de ética, uma vez que no ato violento não se vê o outro, não se percebe a humanidade daquele que está sendo atingido. Este é coisificado, desprovido de sua condição de ser humano, tratado como objeto. (....) Geralmente, aquele que violenta também sofreu a violência, também foi coisificado (...). Trata-se da perpetuação de um ciclo. (MAGALHÃES, 2003, p.4).

Portanto, diante do exposto, é possível afirmar que a violência contra a mulher é qualquer ação ou conduta que causa morte, dano ou sofrimento físico, sexual ou psicológico à mulher. Dentre as espécies de violência, o presente capítulo destaca a violência sexual.

A Lei de ${ }^{\circ}$. 11.340, de 2006, mais conhecida como a Lei Maria da Penha, originou-se pela necessidade de uma regulamentação protetiva às mulheres e trouxe grandes inovações jurídicas e processuais para tratar da complexidade da violência doméstica. Essa legislação discorre sobre a violência sexual da seguinte forma:

Artigo $7^{\circ}$, inciso III- a violência sexual, entendida como qualquer conduta que a constranja a presenciar, a manter ou a participar de relação sexual não desejada, mediante intimidação, ameaça, coação ou uso da força; que a induza a comercializar ou a utilizar, de qualquer modo, a sua sexualidade, que a impeça de usar qualquer método contraceptivo ou que a force ao matrimônio, à gravidez, ao aborto ou à prostituição, mediante coação, chantagem, suborno ou manipulação; ou que limite ou anule o exercício de seus direitos sexuais e reprodutivos. (2006).

Pelo que se constata, a violência envolve a coisificação do sujeito, ou seja, considera o outro como um objeto e, sendo assim, a mulher se encontra na condição de vulnerabilidade diante essa agressividade. Observa-se, também, que a agressão

13 A psicóloga francesa Jacqueline Barus-Michel. 
factual não é isolada, mas traz consigo a violência emocional e moral, acarretando consequências à saúde mental e à subjetividade dos sujeitos envolvidos.

Na sociedade contemporânea, percebe-se que o termo misoginia tornou-se conhecido e bastante utilizado nos meios de comunicação. Considerado como uma espécie de violência contra a mulher, uma ação de discriminação sexual, que estabelece uma relação de desigualdade entre os gêneros feminino e masculino. Tal termo originou-se na Grécia Antiga com o intuito de conceituar as relações nocivas que ocorrem entre homens e mulheres.

A vida do sujeito do sexo feminino é pautada pela sua condição de ser mulher e isso afeta o modo com que ela se insere nos espaços sociais, sendo considerada incapaz pela forte presença da misoginia, prejudicando o seu desenvolvimento enquanto cidadã. A misoginia, portanto, é um ato de violência contra a mulher, pois acarreta várias modalidades de hostilidades, diminui a dignidade da mesma em diferentes âmbitos sociais e mantém o ciclo violento ao qual ela vivencia.

Ocorre uma aliança entre a violência e a desigualdade de gênero, que nega, desse modo, os direitos inerentes à mulher que, consequentemente, reforça o autoritarismo dos homens, naturalizando e legitimando as brutalidades praticadas por eles. A sociedade brasileira é autoritária e sustenta suas relações com base nas referências patriarcais.

É possível constatar que há uma expectativa comportamental que exige uma demonstração da insensível virilidade do homem e a plena subserviência da mulher. Quando essas ações não ocorrem, a violência aflora gradativamente, iniciando com piadas inapropriadas, assédios, abusos, estupros e culmina com o feminicídio. (CARNEIRO, 2019, p. 2).

Diante do exposto, as ações geradas por estruturas sociais que julgam as mulheres inferiores e incapazes, interferem de modo negativo na vida da mulher, afetando seu meio social, psicológico, econômico e político. As expressões e comportamentos machistas são reproduzidos tanto por homens como por mulheres, inconscientemente. A mulher, por sua vez, ciente da cultura opressora presente na sociedade, se apropria dessa concepção como mecanismo de sobrevivência e defesa.

O poder patriarcal é um símbolo ainda presente na atual sociedade brasileira, de modo que as violências praticadas contra mulheres ainda não são adequadamente reprimidas, na maioria das ocorrências. Em suma, é possível concluir que a origem da violência contra a mulher é cultural.

Tendo o devido conhecimento do desenvolvimento da sociedade e da implantação de medidas protetivas, de punição aos agressores, compreende-se que o comportamento e pensamento dos sujeitos que infringem a dignidade da mulher, ainda não incorporaram a idealização de ações que requeiram transformação pessoal para que haja, dessa forma, o pleno gozo da cidadania feminina.

A desigualdade de gênero se consolida no seio familiar, sendo o primeiro ambiente social a construir regras de comportamento, tendo a figura masculina o título de provedor do lar, trazendo consigo a ideologia machista, sendo culturalmente mantida e solidificada pela sociedade, ao longo dos anos. Em consonância com a 
realidade social, o ordenamento jurídico possuía brechas ocultas que legitimavam crimes praticados por homens.

O conhecido e antigo ditado popular "por trás de um grande homem, sempre existe uma grande mulher" delimita o espaço da mesma, firmando a ideia de que a mulher ocupa um papel secundário ao do homem, atuando no campo doméstico e familiar somente.

A mulher teve seu reconhecimento legal e efetivo na Constituição Federal de 1988. O artigo $5^{\circ}$ apresenta as garantias e os direitos fundamentais a todo e qualquer cidadão e o caput do mesmo artigo afirma que "todos são iguais perante a lei, sem distinção de qualquer natureza...". Foi necessário adicionar ao corpo da Lei Maior tal previsão para se estabelecer o idealismo de igualdade entre todos os cidadãos e cidadãs. Percebe-se que ao longo dos anos conquistas ocorreram e a legislação vem se encarregado de garantir mais direitos a quem necessita de maior proteção.

O tema violência é gênero para o Direito Penal e traz consigo o conceito de que é uma ofensa à integridade física ou mental de outrem, acrescido de grave ameaça e vias de fato, em sentido amplo. Essa concepção é dividida em vis corporalis, sendo a violência empreendida sobre o corpo da vítima e, vis compulsivas, que corresponde a grave ameaça. (LACERDA, 2018, p. 1).

A violência é um problema que perpassa gerações e que presumivelmente manifestou-se concomitantemente com a unidade familiar, sem distinção de classe social e etnia; a violência contra a mulher é um fato existente.

A Lei Maria da Penha é a principal legislação do Brasil de proteção às mulheres vítimas de violência doméstica. A legislação determina a prisão do suspeito de agressão, trata a violência em casa como agravante de aumento de pena, ordena o afastamento do agressor da vítima e de sua família, e garante a assistência econômica em caso de dependência financeira da mulher. (CERIONI, 2019, p. 2).

A advogada especialista em direito público e econômico Monica Sapucaia, também co-autora do livro "Women's Rights International Studies on Gender Roles" (2018) afirma que a instituição da Lei Maria da Penha trouxe mudanças significativas para a questão da violência doméstica. Contudo, essa problemática social ainda é muito presente na sociedade; mesmo quando a legislação é boa, as políticas públicas não dão respaldo para a execução dessa questão. É possível certificar a afirmação da advogada, considerados os dados estatísticos de feminicídios registrados no Brasil anualmente.

O princípio da dignidade da pessoa humana é de grande valia por colocar o indivíduo no centro protetor do Direito. Na doutrina, Manual de Direito das Famílias, a autora, Maria Berenice Dias disserta sobre o tema.

Trata-se do princípio fundante do Estado Democrático de Direito, sendo afirmado já no primeiro artigo da Constituição Federal. A preocupação com a promoção dos direitos humanos e da justiça social levou o constituinte a consagrar a dignidade da pessoa humana como valor nuclear da ordem constitucional. Sua essência é difícil de ser capturada em palavras, mas incide sobre uma infinidade de situações que dificilmente 
se consegue elencar de antemão. Talvez possa ser identificado como o princípio de manifestação primeira dos valores constitucionais, carregado de sentimentos e emoções e experimentado no plano dos afetos. (DIAS, 2016, p. 74).

O ser humano é um ser sociável e, diante da evolução e complexidade do relacionamento em coletividade, novos direitos foram criados em virtude da busca pela convivência pacífica. O maior direito essencial e fundamentado pela Constituição Federal/ 88 é a dignidade da pessoa humana, que norteia a vida em sociedade e em todas as ações realizadas nos âmbitos nacional e internacional.

O professor de Direito Constitucional, Dirley da Cunha Júnior (2020, p. 250), aponta que

A dignidade, em si, não é um direito, mas uma qualidade intrínseca a todo ser humano, independentemente de sua origem, sexo, idade, condição social ou qualquer outro requisito. Nesse sentido, não pode ser considerada como algo relativo. (JÚNIOR, 2020, p. 250)

Logo, nesse sentido, ainda que de acordo com o autor supracitado, a dignidade é direito de todos " independentemente de sua origem, sexo, idade ..." (JÚNIOR, 2020, p. 250). Percebe-se que a realidade que permeia a dignidade vivenciada pela mulher não alcançou em sua totalidade todos os direitos apresentados; nota-se a existência de algumas conquistas nesta trajetória de busca por direitos.

\section{CONSIDERAÇÕES FINAIS}

Após a imersão nas leituras realizadas, apropriamo-nos dos conhecimentos e saberes que envolvem o universo da pornografia e violência contra a mulher, não da forma pormenorizada e detalhada que o assunto nos instiga e motiva a buscar. Apresentamos a seguir alguns apontamentos que este artigo nos proporcionou perceber.

Assim, compreendemos que o diálogo e o autoconhecimento são fontes valiosas para a evolução do ser humano. O conhecimento e aprendizado adquiridos ao longo da existência são fundamentais para uma vida sadia e harmônica para com os demais indivíduos da sociedade.

Observamos que o homem é o grande protagonista dos filmes pornôs, em sua maioria, enquanto que as mulheres ali atuando servem como meio de obtenção desse prazer explicitamente revelado na tela. Percebemos que em algum momento isso pode afetar a realidade das relações sexuais, pois a idealização do sexo gerada pela influência da indústria pornográfica, por certo, contribui negativamente nas relações pessoais. Ocorre, também, a submissão das mulheres às práticas impostas pelos parceiros, devido à falta de incentivo das mesmas explorarem a própria sexualidade, descobrindo seus gostos e preferências, é o desconhecimento do seu corpo e do seu prazer.

É assim gerada uma imagem de que o feminino está a serviço dos desejos sexuais do homem, a partir da vulgarização do sexo e da desvalorização da mu- 
lher, promovidas pelos vídeos pornográficos. Este é um meio que se mantém e cresce conforme o procurado pelos consumidores.

Diante do exposto, há de se pensar: em qual momento da história o sexo feminino passou a ser objeto para o sexo masculino? É crescente o índice de violência sofrida por mulheres, sendo possível constatar tal fato pelas constantes reportagens nos meios de comunicação, com relatos de casos e também pelos dados estatísticos. Como citado, os maiores casos de violência ocorrem dentro do âmbito familiar.

A legislação brasileira, supracitada no Título II, é relevante para o combate à violência sofrida por mulheres. $\mathrm{O}$ texto legal é severo quanto à sua aplicação, como, por exemplo, a Lei Maria da Penha, que trouxe por meio da sua aplicação mudanças significativas nesse contexto social.

Porém, como em muitas leis, há sempre aquela possibilidade de pender para um lado ou para o outro, ou seja, existem brechas que precisam ser eliminadas. Há espaços para debates e propostas para melhor amparo e divulgação de informação. No entanto, é possível observar que a falta de mudanças no jeito de pensar e agir dos homens, faz perdurar as espécies de violência, e a lei por si só não é suficiente para coibir o ímpeto masculino.

Tendo em vista os apontamentos dos estudos de Freud, é possível observar e certificar que desde a infância ocorre o desenvolvimento da sexualidade, o seu afloramento e descobertas no decorrer das experiências vividas. Porém, questionamos: em que tempo ou fase a sexualidade do indivíduo é corrompida ao ponto de aceitar e se satisfazer com a violência empregada nos vídeos pornôs? Certamente são indagações para estudos futuro.

A pornografia nasceu com o olhar de desejo do ser humano sobre os corpos, sendo possível sentir o "despertar" dos desejos sexuais e sua satisfação. Há séculos vem acompanhando o desenvolvimento da humanidade, passando por diversas mudanças, até chegar ao que se tem apresentado atualmente. É uma fonte que facilita o desenvolvimento de uma relação sexual.

Constatamos que a pornografia pode ser algo saudável para a vida, dependendo de como a mesma é consumida. No entanto, também deve ser analisada a forma como a mesma é produzida e disseminada. Atualmente, ela representa a expressão da sexualidade agressiva do homem. A produção de conteúdos pornográficos confirma que de fato é previsível em nossa sociedade a dominação masculina, cuja agressividade é culturalmente naturalizada.

A indústria pornográfica tem se firmado em dar acessibilidade e, proteção aos seus consumidores, por meio das produções e reproduções de seus conteúdos. Ocorreu uma grande inserção da pornografia pela aproximação com o consumidor devido os avanços da internet.

De acordo com Freud, podemos afirmar que muitas ações realizadas na fase adulta, decorrem de acontecimentos desde a fase inicial da vida. Sabe-se, também, que os desejos sexuais são subjetivos, não há como padronizar o que pode dar prazer a alguém. A ausência de uma sexualidade saudável pode acarretar transtornos à própria vida e pode vir a afetar a de terceiros, seja ele uma pessoa próxima ou o terceiro presente nos vídeos pornográficos. 
A ausência de referências familiares, independente da espécie, pode gerar grandes danos à vida de uma pessoa, em suas mais diversas áreas, podendo ser observados os reflexos ao longo de sua jornada. $\mathrm{O}$ ato de disponibilizar um aparelho eletrônico para uma criança pode acarretar em problemas na visão, dificuldade de desenvolver a fala, interação com as demais pessoas e, dentre outras disfunções, pode propiciar uma experiência precoce com relação aos infindáveis materiais pornográficos de livre acesso na internet, fazendo com que crie uma falsa memória sobre sexo e sexualidade.

A participação dos responsáveis na educação de uma criança é fundamental para que mudanças futuras ocorram. O diálogo sobre a sexualidade é assunto de grande valia para um desenvolvimento saudável de uma criança, pois a falta de conhecimento, discernimento e maturidade da mesma poderá desencadear danos que posteriormente trarão consequências negativas ao sujeito em sua fase adulta, podendo afetar terceiros.

Não há dados coletados suficientes para comprovar que existe uma relação entre a pornografia e a violência sofrida pelas mulheres. Não encontramos uma pesquisa acurada que confirme o questionamento deste artigo. Mas nos atentamos ao fato da importância do diálogo e participação ativa dos adultos para com as fases iniciais de uma pessoa.

Que este artigo possa trazer um novo olhar sobre a sexualidade dos indivíduos e o modo como a desenvolvemos e, também, o acesso e excesso aos conteúdos pornográficos, além de suscitar em novas pesquisas e estudos relevantes sobre essa temática.

\section{REFERENNCIAS}

ABREU, Nuno Cesar. O olhar pornô: A representação do obsceno no cinema e no vídeo. 2 ed. São Paulo: Alameda, 2012.

AIDAR, Laura. História do Cinema Brasileiro. Toda Matéria, São Paulo, 29 jan. 2018. Artes. Disponível em: https://www.todamateria.com.br/historia-do-cinema-brasileiro/ Acesso em: 20 mar. 2020.

ALEXANDRIAN, Sarane. História da literatura erótica. 2 ed. São Paulo: Rocco, 1994.

ALMEIDA, Júlio César da Silva. O princípio da igualdade, elemento indicador da necessidade de regulamentação do direito à liberdade sexual. JusBrasil, Brasil, 4 maio 2013. Disponível em: https://jus.com.br/artigos/24516/o-principio-da-igualdade-elemento-indicador-da-necessidade-de-regulamentacao-do-direito-a-liberdade-sexual Acesso em: 24 maio 2020.

AQUINO, Manuela. Pornografia feminista não existe. Uol - Revista TPM, São Paulo, 27 mai. 2019. Disponível em: https:/ / revistatrip.uol.com.br/tpm/a-feminista-e-ativista-antipornografia-gail-dines-fala-porno-e-comportamento-masculino Acesso em: 29 nov. 2019

BARBOSA, Amanda Espíndola. Violência contra a Mulher - Legislação Nacional e Internacional. JusBrasil, Brasil, ano 2017, n. 119, p. 1-2, 3 jun. 2013. Disponível em: https:// 
eduardocabette.jusbrasil.com.br/artigos/121937941/violencia-contra-a-mulher-legislacao-nacional-e-internacional-por-amanda-espindola-barbosa Acesso em: 20 abr. 2020.

BARREIROS, Isabela. A inusitada maneira como as pessoas lidavam com o sexo na idade antiga. Aventuras na história, São Paulo, 30 abr. 2020. Disponível em: https:/ / aventurasnahistoria.uol.com.br/noticias/almanaque/historia-como-pessoas-lidavam-com-o-sexo-na-idade-antiga.phtml Acesso em: 7 mai. 2020.

BEAUVOIR, Simone. O segundo sexo - 2. A experiência vivida. Vol. V. Rio de Janeiro: Nova Fronteira, 1949.

BERNARDET, Jean Claude. Brasil em tempo de cinema. Rio de Janeiro: Paz \& Terra, 1978.

CANAL TECH, Redação. Pornhub divulga estatísticas de 2017 e mostra que brasileiro adora pornografia. Canal Tech, [S. l.], 9 jan. 2018. Disponível em: https:/ / canaltech.com. br/comportamento/pornhub-divulga-estatisticas-de-2017-e-mostra-que-brasileiro-adora-pornografia-106304/ Acesso em: 2 abr. 2020.

CANDIDO, Marcos. O que o consumo de pornografia diz sobre a sexualidade do brasileiro?. UOL, São Paulo, 29 jan. 2018. Sexo. Disponível em: https:/ /www.uol.com.br/universa/noticias/redacao/2018/01/29/o-que-o-consumo-de-pornografia-diz-sobre-a-sexualidade-do-brasileiro.htm Acesso em: 2 abr. 2020.

CARNEIRO, Yanna J. Misoginia: você sabe o que é?. Politize, Brasil, ano 2010, 5 ago. 2019. Disponível em: https:/ /www.politize.com.br/misoginia/ Acesso em: 22 abr. 2020.

CARVALHO, Gisele Mendes de. CHAGAS, Edmar José. Proteção da Dignidade Sexual Ou Paternalismo Jurídico: A Propósito do valor do consentimento do menor de 14 anos no Crime de Estupro de Vulnerável, São Paulo, ano 2015. Disponível em: http:/ / www. publicadireito.com.br/artigos/?cod=e721a54a8cf18c85 - Acesso: 10 mai.2020

CARVALHO, Maria Tereza Queiroz. Lei Maria da Penha e a dignidade da mulher enquanto pessoa humana. JusBrasil, Brasil, 20 ago. 2014. Disponível em: https://jus.com. br/artigos/31366/lei-maria-da-penha-e-a-dignidade-da-mulher-enquanto-pessoa-humana Acesso em: 24 maio 2020.

CARVALHO, Renata Augusto de. Erotismo e a intertextualidade: na narrativa de Márcia Denser. Orientador: Ana Lúcia Trevisan Pelegrino. 2008. 90 f. Dissertação (Mestrado em Literatura) - Universidade Presbiteriana Mackenzie, São Paulo, 2008. Disponível em: http:/ / tede.mackenzie.br/jspui/bitstream/tede/2275/1/Renata \%20Augusto $\% 20 \mathrm{de} \% 20$ Carvalho.pdf. Acesso em: 26 jan. 2020.

CERIONI, Clara. As leis brasileiras sobre direitos das mulheres - e os avanços necessários. Exame, Brasil, 8 mar. 2019. Disponível em: https://exame.abril.com.br/brasil/ as-leis-brasileiras-sobre-direitos-das-mulheres-e-os-avancos-necessarios/ Acesso em: 10 maio 2020.

CHAUÍ, Marilena. Ensaio: ética e violência. Revista Teoria e Debate n. 39. São Paulo: Perseu Abramo, 1998. 
DI ANGILLIS, Guilherme. O erótico da pornografia: as imagens, sons, e escritas nas representações sobre sexo. Canal Gleici Duarte, 2016. Disponível em: https:/ / www.youtube.com/watch?v=HL9VrLGVBLA Acesso em: 22 novembro 2019.

DIAS, Maria Berenice. Manual de Direito das Famílias. 11ª ed. Revista dos Tribunais. São Paulo. 2016

DANTAS, Bruna Suruagy do Amaral. Sexualidade, cristianismo e poder. Orientador: Abimar Oliveira de Moraes. 2010. 12 f. Dissertação (Psicologia social) - PUC-SP, São Paulo, 2010. Disponível em: http://www.revispsi.uerj.br/v10n3/artigos/html/v10n3a05.html Acesso em: 10 maio 2020.

DRECHSEL, Denise. Exposição à pornografia deixa marcas para toda a vida. Gazeta do Povo, Brasil, 3 jun. 2016. Educação. Disponível em: https://www.gazetadopovo.com.br/ educacao/exposicao-a-pornografia-deixa-marcas-para-toda-a-vida-5png4102owakft4lkgayjumvw / Acesso em: 2 maio 2020.

FERREIRA, Breno de Oliveira; MENESES, Hélem Soares de. Pervesão à Luz da Psicanálise. Psicologado, Brasil, 1 nov. 2011. Disponível em: https://psicologado.com.br/abordagens/psicanalise/perversao-a-luz-da-psicanalise Acesso em: 14 abr. 2020.

FONSECA, Isabelle Christina Teixeira. A música como linguagem e comunicação à luz do estudo teológico-pastoral. Orientador: Abimar Oliveira de Moraes. 2017. 8 f. Dissertação (Teologia) - PUC-RIO, Rio de Janeiro, 2017. Disponível em: http:/ / www.puc-rio.br/ pibic/relatorio_resumo2017/relatorios_pdf/ctch/TEO/TEO-Isabelle \% 20Christina \% 20 Teixeira\%20Fonseca.pdf Acesso em: 2 abr. 2020.

FREUD, Sigmund. Um caso de histeria. Três ensaios sobre a teoria da sexualidade. Volume VII. IMAGO: São Paulo,1925.

Internacional de Cinema, Brasil, 23 fev. 2019. Movimentos Cinematográficos, p. 167-190. Disponível em: https://www.aicinema.com.br/a-historia-do-cinema-brasileiro/ Acesso em: 2 maio 2020.

JÚNIOR, Dirley da Cunha. Curso de Direito Constitucional. 14 ed. Salvador: JusPodivm, 2020

KREUTZ, Katia. A História do Cinema Brasileiro. AICinema - Academia Internacional de Cinema, Brasil, 23 fev. 2019. Movimentos Cinematográficos, p. 167-190. Disponível em: https:/ / www.aicinema.com.br/a-historia-do-cinema-brasileiro/ Acesso em: 2 maio 2020.

LACERDA, Isadora Almeida. O conceito de violência contra a mulher no direito brasileiro. Orientador: Adriana Vidal. 2014. 19 f. Dissertação (Direito) - PUC-RIO, Rio de Janeiro, 2014. Disponível em: http://www.puc-rio.br/pibic/relatorio_resumo2014/relatorios_ pdf/ccs/DIR/DIR-Isadora\%20Almeida\%20Lacerda.pdf Acesso em: 20 abr. 2020.

LEAL, Raphael Barros; CABRAL, Flavio José Gomes. Religião e Sexo: do controle na idade média e sua herança na contemporaneidade. 2010. 11 f. Dissertação (Teologia) - Universidade Católica de Pernambuco (UNICAP), Pernambuco, 2010. Disponível em: http:/ / www.unicap.br/coloquiodehistoria/wp-content/uploads/2013/11/4Col-p.572.pdf Acesso em: 23 fev. 2020. 
MAINGUENENAU, Dominique. O discurso pornográfico. Rio de Janeiro: Parábola Editorial. 2010

MAGALHÃES, Jaqueline Soares. Abuso sexual intrafamiliar: reflexões sobre um caso clínico sob a perspectiva da psicanálise do self. Dissertação (Mestrado). São Paulo: Universidade de São Paulo - USP, 2003

MANSSUR, Gabriela. Os princípios jurídicos constitucionais aplicados: aos crimes contra a dignidade sexual. Justiça de Saia, São Paulo, ano 2019, 4 jan. 2019. Direitos da mulher, p. 1-1. Disponível em: http:/ / www.justicadesaia.com.br/os-principios-juridicos-constitucionais-aplicados-aos-crimes-contra-a-dignidade-sexual/

NUNO, Fernando - traduziu. O livro do cinema. 1 ed. Globo livros. São Paulo. 2016

RAMOS, Jefferson Evandro Machado. Deuses Gregos. Sua Pesquisa, São Paulo, 4 mar. 2011. Arte e literatura. Disponível em: https://www.suapesquisa.com/musicacultura/ deuses_gregos.htm Acesso em: 20 mar. 2020

REALE, Miguel. Lições preliminares de direito. 27ª Ed. São Paulo: Saraiva, 2009

RIBEIRO, Paulo Rennes Marçal. A sexualidade também tem história: comportamentos e atitudes sexuais através dos tempos. In.: BORTOLOZZI, Ana Claúdia; MAIA, Ari Fernando (Org). Sexualidade e infância. Bauru: FC/CECEMCA; Brasília: MEC/SEF, 2005, p.17-32

SMANIO, Gianpaolo Poggio; FABRETTI, Humberto Barrionuevo. Introdução ao Direito Penal. São Paulo: Ed. Atlas, 2017

VALAS, Patrick. Freud e a perversão. Tradução: Dulce Duque Estrada. Rio de Janeiro: Jorge Zahar, 1997.

VINHAL, Gabriela; LEITE, Hellen. Reféns de pornografia contam como a compulsão transtornou suas vidas. Correio Braziliense Revista, Brasil, 19 mar. 2018. Disponível em: https:/ / www.correiobraziliense.com.br/app/noticia/revista/2018/03/18/interna_revista_correio,666601/refens-de-pornografia-contam-como-a-compulsao-transtornou-suas-vidas.shtml Acesso em: 2 maio 2020. 